\title{
Relation of Human Papilloma Virus Infection with Pre Malignant and Malignant Endometrial Lesions
}

\author{
Mahmoud Mohammed Mahmoud ${ }^{1}$, Aseel Ghazi Rifat ${ }^{2}$ \\ ${ }^{1}$ Assistant Professor in the Department of Pathology, College of Medicine, University of Kirkuk, Kirkuk, Iraq, \\ ${ }^{2}$ Assistant Professor in the Department of Gynecology \& Obstetrics, College of Medicine, University of Kirkuk, \\ Kirkuk, Iraq
}

\begin{abstract}
Endometrial carcinoma is the second most common gynecologic cancer worldwide. Hyperplasia is a precursor to endometrioid adenocarcinoma. There are few studies on the association of HPV with endometrial adenocarcinoma.
\end{abstract}

Aim of the Study: To determine the relation of HPV with premalignant and malignant endometrial lesions.

Patients and Method: This study achieved on a total number of 90 patients with histopathological examination revealing endometrial hyperplasia in 30 patient, endometrial carcinoma in 30 patient in addition to 30 cases who underwent hystrectomy, for all patients detection of HR-HPV done by RT-PCR.

Results: The HR-HPV positivity was recorded in 23 patients. For the studied cases with endometrial carcinoma, endometrial hyperplasia and controls the positivity rates were about (16.7\%), (36.7\%) and (23.3\%) respectively. Highest rate of HR-HPV positivity for the studied patients was found in the age group (45-49). Highest rate of HR-HPV positivity in cases with endometrial carcinoma was reported in older age groups [(45-49) and (50-54)], compared to endometrial hyperplasia and controls [(40-44) and (45-49)]. The HR-HPV positivity was most frequently observed in cases with well-differentiated (22.2\%). Higher HRHPV positivity rate was reported in the hyperplasia without atypia.

Conclusion: No role of HR-HPV in the pathogenesis of endometrial carcinoma.

Keywords: HPV, endometrial carcinoma, hyperplasia.

\section{Introduction}

Endometrial carcinoma is the most common gynecologic cancer in high-income countries and the second most common gynecologic cancer worldwide when both high and low-income countries are considered $^{(1)}$. In Iraq although it is not within the top

\section{Corresponding Author:}

Mahmoud Mohammed Mahmoud

Assistant Professor in the Department of Pathology, College of Medicine, University of Kirkuk, Kirkuk, Iraq

e-mail: mahmoud_mm1973@yahoo.com

Telephone No.: +9647701306008 ten cancers and it account for $0.56 \%$ of total malignant tumor ${ }^{(2)}$. Endometrial cancer is often detectable in the early stages due to the nature of the disease with the 5 -year survival rate of $85-91 \%$. About $73 \%$ of patients with endometrial cancer are diagnosed in stage I. It is, therefore, very important to identify risk factors followed by primary diagnostic interventions to modify the factors effective on cancer ${ }^{(3-8)}$. Human papilloma virus is one of the most obvious risk factors for cancer ${ }^{(9)}$. Since its recognition as the cause of cervical cancer, this infectious agent has been the focus of intensive researches ${ }^{(10)}$.Human papilloma virus is the most common sexually transmitted infection worldwide. It is also the causative agent for $1 / 3$ of all the viral induced tumors and responsible for $(5 \%)$ of human cancers ${ }^{(11)}$. Human papilloma virus is subdivided into two major 
subgroups, namely the low-risk HPVs which are mainly associated with development of warts and benign lesions and high-risk HPVs (e.g 16, 18, 31, 33, 45, 51, 52, 56, $58,59,68,73 \& 82)$ which are considered the main drivers of high-grade lesions and cancers" ${ }^{\prime 2}(12,13,14)$.

\section{Material and Method}

This case-controlled observational study achieved during the period from January 2018 to January 2020 through which a total number of 90 patients were recuruited between $30-71$ years of age, who were admitted to the department of Gynecology and Obstetrics in Azadi teaching hospital and private hospitals in Kirkuk city for whom hystrectomy was done for various indications after full clinical assessment with histopathological examination of the hystrectomy specimens and were divided into three groups according to the results of the histopathology consisting of 30 patints with endometrial hyperplasia,30 patients with endometrial carcinomain addition to 30 cases with normal endometrium who underwent hystrectomy for catastrophic obstetricalemergencies or for other benign conditions related to tubes, ovaries and uterine corpus like uterine prolapse and leiomyomasas a control group. For all the cases a full history was taken, general and pelvic examination was done, Pap smear was performed in addition to the routine laboratory investigations prior to surgery. Patients with previous history of malignant disease involving the genetal tract or history of vulvar, vaginal or cervical HPV related lesions, intraepithelial neoplasia and carcinoma or abnormal pap smear results were excluded from the study.

Tissue sections were obtained from these patientsbiopsy specimens following hystrectomy in the histopathology laboratories. The histopathological types of endometrial carcinoma and endometrial hyperplasia were classified according to WHO classification ${ }^{(17)}$ and the endometrial carcinoma was staged according to FIGO satging system.For the three groupsof endometrial carcinoma, hyperplasia and controls the detection of 12 types of HR-HPV DNA (types16, 18, 31, 33, 35,39, 45, $51,52,56,58 \& 59)$ using real time polymerase chain reaction in molecular laboratory was done. The variables were analyzed using stratified chi-square and Fisher's exact tests. A statistical test considered significant when the $\mathrm{p}$-value was $\leq 0.05$.

Findings: The clinico-pathological data of the studied cases are summarized in table (1). the studied patients were categorized into nine groups according to the age. The mean age of participants was (53.96) years and the median was (56) years. There was no patient younger than 30 years or older than 71 years.

Most of endometrial carcinomas were in the age groups (65-69) years of age ( 9 cases), with absence of any cases in the age groups below 39 years while the endometrial hyperplasia cases were mostly distributed between the age groups (40-44), (45-49), (50-54) \& (5559) years .

All of endometrial carcinoma were of endometrioid type either well, moderately or poorly differentiated type. The well-differentiated endometrial carcinoma were presented in $(60 \%)$ of cases,while moderate \& poorly differentiated tumors were present in $(33.3 \%)$ and $(6.7 \%)$ of patientswith carcinoma respectively, no any squamous differentiation was denoted in this study.

Of the 30 cases of endometrial hyperplasia, 18 $(60 \%)$ of cases were hyperplasia without atypia while 12 $(40 \%)$ of cases were atypical hyperplasia/endometrioid intraepithelial neoplasia as shown in (table 1).

Table 1: Endometrial histology pattern according to the age groups.

\begin{tabular}{|c|c|c|c|c|c|c|c|c|c|c|c|}
\hline \multicolumn{2}{|c|}{ Endometrial histology } & $30-34$ & 35-39 & $40-44$ & $45-49$ & $50-54$ & $55-59$ & $60-64$ & $65-69$ & $70+$ & Total \\
\hline \multirow{3}{*}{$\begin{array}{l}\text { Endometrial } \\
\text { carcinoma }\end{array}$} & Well-differentiated & 0 & 0 & 1 & 2 & 2 & 4 & 4 & 4 & 1 & $18(60 \%)$ \\
\hline & Moderately-differentiated & 0 & 0 & 0 & 0 & 0 & 2 & 3 & 4 & 1 & $10(33.3 \%)$ \\
\hline & Poorly-differentiated & 0 & 0 & 0 & 0 & 0 & 0 & 0 & 1 & 1 & $2(6.7 \%)$ \\
\hline \multirow[b]{2}{*}{$\begin{array}{l}\text { Endometrial } \\
\text { hyperplasia }\end{array}$} & Hyperplasia without atypia & 2 & 3 & 5 & 4 & 2 & 2 & 0 & 0 & 0 & $18(60 \%)$ \\
\hline & $\begin{array}{l}\text { Atypical hyperplasia/ } \\
\text { endometrioid intraepithelial } \\
\text { neoplasia }\end{array}$ & 0 & 0 & 1 & 1 & 3 & 4 & 2 & 1 & 0 & $12(40 \%)$ \\
\hline \multicolumn{2}{|l|}{ Control cases } & 3 & 3 & 5 & 6 & 5 & 3 & 3 & 2 & 0 & $30(100 \%)$ \\
\hline \multicolumn{2}{|l|}{ Total } & 5 & 6 & 12 & 13 & 12 & 15 & 12 & 12 & 3 & 90 \\
\hline
\end{tabular}


Overall HR-HPV positivity was recorded in $25.6 \%$ (in 23 cases) of the patients included in the study. For the studied cases with endometrial carcinoma, endometrial hyperplasia and controls the positivity rates were about (16.7\%), (36.7\%) and (23.3\%) respectively. Although the HR-HPV positivity appear higher in endometrial hyperplasia group but the analysis did not identify any statistically significant difference between the three groups as shown in table (2).

Table 2: Frequency distribution of HR-HPV in studied groups.

\begin{tabular}{|c|c|c|c|c|c|}
\hline Studied Groups & HR-HPV (+) No. (\%) & HR-HPV (-) No (\%) & Total & $\mathbf{X}^{2}$ & P-value \\
\hline Endometrial carcinoma & $5(16.7)$ & $25(83.3)$ & 30 & \multirow{4}{*}{3.2706} & \multirow{4}{*}{0.194894} \\
\hline Endometrial hyperplasia & $11(36.7)$ & $19(63.3)$ & 30 & & \\
\hline Control & $7(23.3)$ & $23(76.7)$ & 30 & & \\
\hline Total & $23(25.6)$ & $67(74.7)$ & 90 & & \\
\hline
\end{tabular}

Table (3) shows the distribution of HR-HPV positive cases in the three groups of endometrial carcinoma, hyperplasia and controls according to the age groups. Overall the highest rate of HR-HPV positivity for the studied patients was found in the age group (45-49). In cases with endometrial carcinoma higher rate of HR-
HPV positivity was reported in older age groups[(45-49) and (50-54)], compared to endometrial hyperplasia and controls[(40-44) and (45-49)], however this difference in the distribution of HR-HPV positivity according to age groups in the three studied groups was statistically unsignificant.

Table 3: Distribution of positive HR-HPV cases in different age groups .

\begin{tabular}{|c|c|c|c|c|}
\hline Age groups & $\begin{array}{c}\text { Endometrial carcinoma } \\
\text { No. (\%) }\end{array}$ & $\begin{array}{c}\text { Endometrial hyperplasia } \\
\text { No. (\%) }\end{array}$ & $\begin{array}{c}\text { Control group } \\
\text { No. (\%) }\end{array}$ & $\begin{array}{c}\text { Total No } \\
(\%)\end{array}$ \\
\hline $30-34$ & $0(0)$ & $1(9.1)$ & $1(14.3)$ & $2(8.7)$ \\
\hline $35-39$ & $0(0)$ & $2(18.2)$ & $1(14.3)$ & $3(13)$ \\
\hline $40-44$ & $1(20)$ & $3(27.3)$ & $2(28.6)$ & $6(26)$ \\
\hline $45-49$ & $2(40)$ & $3(27.3)$ & $2(28.6)$ & $7(30.4)$ \\
\hline $50-54$ & $2(40)$ & $1(9.1)$ & $1(14.3)$ & $4(17.4)$ \\
\hline $55-59$ & $0(0)$ & $1(9.1)$ & $0(0.0)$ & $1(4.3)$ \\
\hline $60-64$ & $0(0)$ & $0(0)$ & $0(0.0)$ & $0(0.0)$ \\
\hline $65-69$ & $0(0)$ & $0(0)$ & $0(0.0)$ & $0(0.0)$ \\
\hline $70+$ & $0(0)$ & $0(0)$ & $0(0.0)$ & $0(0.0)$ \\
\hline Total & $\mathbf{5 ( 1 0 0 )}$ & $\mathbf{1 1}$ & $\mathbf{7}$ & $\mathbf{2 3}$ \\
\hline
\end{tabular}

*Fisher-exact test. Regarding the association of HR-HPV positivity with the grade (differentiation) of endometrial carcinoma, the HR-HPV positivity was most frequently observed in cases with well-differentiated
(22.2\%) compared to moderate and poorly-differentiated tumors, however this difference was statistically not significantas shown in table (4). 
Table 4: Frequency distribution of HR-HPV positivity in different grades of endometrial carcinoma.

\begin{tabular}{|l|l|c|c|c|c|c|}
\hline \multirow{3}{*}{$\begin{array}{l}\text { Endometrial } \\
\text { carcinoma }\end{array}$} & Grade of differentiation & $\begin{array}{c}\text { HR-HPV (+) } \\
\text { No. (\%) }\end{array}$ & $\begin{array}{c}\text { HR-HPV (-) } \\
\text { No (\%) }\end{array}$ & Total No. (\%) & \multirow{2}{*}{$\mathbf{X}^{\mathbf{2}}$} & \multirow{2}{*}{ p-value } \\
\cline { 2 - 5 } & Well-differentiated & $4(22.2 \%)$ & $14(77.8 \%)$ & $18(100)$ & & \\
\cline { 2 - 5 } & Moderately-differentiated & $1(10 \%)$ & $9(90)$ & $10(100)$ & \multirow{2}{*}{0.6547} & \multirow{2}{*}{0.418442} \\
\cline { 2 - 5 } & Poorly-differentiated & $0(0.0 \%)$ & $2(100 \%)$ & $2(100)$ & & \\
\hline \multicolumn{2}{|c|}{ Total } & $\mathbf{5 ( 1 6 . 7 )}$ & $\mathbf{2 5 ( 8 3 . 3 )}$ & $\mathbf{3 0}(\mathbf{1 0 0})$ & & \\
\hline
\end{tabular}

In the current study 25 patients with endometrial carcinoma were of stage I and 5 patients were of stage II cancer and no cases with stage III and IV carcinoma were reported. In addition our data analysis did not observe any statistically significant differences between HR-HPV positivity and tumor staging as shown in table (5).

Table 5: Frequency distribution of HR-HPV in different stages of endometrial carcinoma.

\begin{tabular}{|l|c|c|c|c|c|c|}
\hline \multirow{4}{*}{$\begin{array}{l}\text { Endometrial } \\
\text { carcinoma }\end{array}$} & Stage (FIGO) & $\begin{array}{c}\text { HR-HPV (+) } \\
\text { No. (\%) }\end{array}$ & $\begin{array}{c}\text { HR-HPV (-) No } \\
\mathbf{( \% )}\end{array}$ & Total No. (\%) & \multirow{2}{*}{$\mathbf{X}^{\mathbf{2}}$} & \multirow{2}{*}{ p-value } \\
\cline { 2 - 5 } & I & $4(16)$ & $21(84)$ & $25(83.3)$ & & \\
\cline { 2 - 5 } & II & $1(20)$ & $4(80)$ & $5(16.7)$ & \multirow{2}{*}{0.048} & \multirow{2}{*}{0.82658} \\
\cline { 2 - 5 } & III & $0(0.0)$ & $0(0.0)$ & $0(0.0)$ & & \\
\hline
\end{tabular}

In the correlation of HR-HPV positivity with the type of endometrial hyperplasia, higher HR-HPV positivity rate was reported in the hyperplasia without atypiacompared to cases withatypical hyperplasia/endometrioid intraepithelial neoplasia however it was statistically non siginificantas shown in table (6).

Table 6: Frequency distribution of HR-HPV in different types of endometrial hyperplasia.

\begin{tabular}{|c|c|c|c|c|c|c|}
\hline \multirow{3}{*}{$\begin{array}{l}\text { Endometrial } \\
\text { hyperplasia }\end{array}$} & Type of hyperplasia & $\begin{array}{l}\text { HR-HPV (+) } \\
\text { No. }(\%)\end{array}$ & $\begin{array}{l}\text { HR-HPV (-) } \\
\text { No (\%) }\end{array}$ & $\begin{array}{l}\text { Total No. } \\
\text { (\%) }\end{array}$ & $\mathrm{X}^{2}$ & P-value \\
\hline & Hyperplasia without atypia & $7(38.8)$ & $11(61.1)$ & $18(100)$ & \multirow{3}{*}{0.0957} & \multirow{3}{*}{0.75706} \\
\hline & $\begin{array}{l}\text { Atypical hyperplasia/endometrioid } \\
\text { intraepithelial neoplasia }\end{array}$ & $4(33.3)$ & $8(66.7)$ & $12(100)$ & & \\
\hline \multicolumn{2}{|r|}{ Total } & $11(36.7)$ & $19(63.3)$ & $30(100)$ & & \\
\hline
\end{tabular}

\section{Discussion}

In the present study, the mean age for endometrial cancer cases was (57.6 yrs). Which was comparable with those reported worldwide revealing that endometrial carcinoma is usually affectingfemales over fifty years of age $^{(18,19)}$ also consistent with other local study ${ }^{(20)}$.

All the cases of endometrial carcinoma in our study were of endometrioid type with no any squamous differentiation was denoted. It is not clear "whether HPV infections can provide morphological changes in the endometrial glandular type epithelium" as far till now "koilocytic changes" have only been reported in the squamous cell carcinoma, adenosquamous carcinoma or squamoid component of some endometrial carcinomas. Based on these changes, "HPV considered not only a traveler but can also stimulate squamous metaplasia in the endometrium"(21).

Regarding histopathological tumor differentiation (grade), in the present study we found that the most prominent grade among endometrial carcinoma cases wasthe well-differentiated (60\%), followed by $(33 \%)$ and $(6.7 \%)$ for moderate \& poorly differentiated respectively this was comparableto results of studies from other countries that reported well-differentiated carcinoma in 
(77\%) of cases compared to (21\%) and (3\%) for moderate and poorly differentiated tumors respectively ${ }^{(22,23)}$ While it was inconsistence with the findings of other national investigator ${ }^{(20)}$ observinga well-differentiated carcinoma in just $(3.3 \%)$ with $(60 \%),(36.7 \%)$ in moderate and poorly-differentiated tumors respectivly. The reason for this discrepancy may be related to the different sample size included in the studies.

Sixity percent of endometrial hyperplasia in the current study were without atypia while $40 \%$ were of atypical endometrial hyperplasia/endometrioid intraepithelial neoplasia type.

The correlation between HPV positivity and age groups in our work show overall, the highest rate of HR-HPV positivity for the patients studied was found in the age group (45-49) (30.4\%). In cases of endometrial carcinoma, higher levels of HR-HPV positivity have been identified in older age groups [(45-49) and (50-54)] relative to endometrial hyperplasia and controls [(4044) and (45-49)], but this disparity in the distribution of HR-HPV positivity by age groups has been recorded, but unfortunately we didn't found any study to compare these datas.

In the current work, HR-HPV was detected in all studied groups including endometrial carcinoma, endometrial hyperplasia and controls, with higher frequency among endometrial hyperplasia $(36.7 \%)$, and to a lesser extent in the control (23.3\%) and endometrial carcinoma $(16.7 \%)$. These figures are close to those reportedin Japanese and Brazelian women ${ }^{(26)}$

and comparable with the results of other studies recording low rate of HR-HPV positivity among patients with carcinoma suggesting non-significant association between HR-HPV infection and endometrial carcinoma $^{(27,28,29)}$ and even failure of detection of HR-HPV in endometrial carcinoma group in other studies $^{(30,31,32)}$.

On the contrary other scientific investigators showed different resultsreporting higher incidence of HR-HPV positivity (63.3\%-87.5\%) in endometrial carcinoma patients ${ }^{(20,25)}$. This discrepancy may be attributed to several factors including the actual methodology such asusing different tissue preparation techniques in these studies like 'frozen section' or'the choice of different detection method for HPV with high false positive results like CISH (chromogenic in situ hybridization) and southern blot hybridization analysis'compared with the high-sensitivity detection method that is $\mathrm{PCR}^{(33)}$ used in the current study.In addition to the difference in the studied populations in relation to non appraisal risk factors (low socioeconomic status, multiple sexual partners, interaction with other sexually transmitted infection, smoking) andto the different HPV genotype observed among popultions in the different countries. Similarly in a recent study from a neighbour country held by Mohammed et al analyzing the association of HPV 16 and 18 with the risk of development of invasive cervical and endometrial carcinoma observed a higher rate of HPV positivity (mainly HPV-18) in cases with endometrial carcinoma (60\%) compared to controls $(29.4 \%)^{(34)}$ again this discripency with our study may be the impact of heterogeneity among the studied groups with regard to age and histological types of endometrial carcinoma and absence of squamous elements (adenocarcinoma with squamous differentiation and squamous cell carcinoma) in any cases of our series.

In the present study although higher HR-HPV positive cases found in endometrial carcinoma with well-differentiated tumors, there was no significant association between HPV positivity and tumor grade. In addition we failed to find any significant association of HPV infection with the progression and stage of the disease. This is consistent with observations of other studies $^{(20,35,36)}$ finding that the presence of HPV in endometrial neoplasm was unrelated to histopathological differentiation, prognostic features and patient survival.

During the current study a higher HPV positive rate was observed in cases of "endometrial hyperplasia without atypia" (38.8\%)compared to "atypical hyperplasia/endometrioid intraepithelial neoplasia" (33.3\%)despite that the difference was not statistically significant. Given that HPV infection is speculated to preceed the progressionto cancer, it is intersting that HPV was detected with less frequency in endometrial hyperplasia at risk of progressing to endometrial carcinoma, namely atypical hyperplasia/endometrioid intraepithelial neoplasia, than those not known to bear such development risk, namely hyperplasia without atypia. This clearly means that HPV can not trigger the oncogenic events atthe endometrium through the sequence of "atypical hyperplasia-neoplasia". In other ward we can say that HR-HPV may play a little carcinogenic effectand this needs other factors like "life style, hormonal, genetic, environmental \& immune deficient state" for progression into malignancy. Consistently a lowerrate of HR-HPV infection 
in “atypical hyperplasia" were reported earlier in other studies $^{(37,38)}$.

\section{Conclusion}

In conclusion these findings may suggest a limited or no role of HR-HPV in the pathogenesis of endometrial carcinoma at least those without squamous elements as the columnar epithelium of the endometrium may not be a convenient host for HR-HPV replication, maturation and neoplastic transformation process.

\section{Ethical Clearance: Yes}

Conflict of Interest: Authors declares none

Funding: Self-funded

\section{Reference}

1. Bray F, Ferly J and Soerjomataram I et al. Global cancer incidence 2018: GLOBOCAN estimates of incidence and mortality worldwide for 36 cancer in 185 countries. Cancer J Clin 2018; 68:394.

2. Iraqi Cancer Board. Results of Iraqi cancer registry center, 2015. Ministry of Health (editor), Baghdad, Iraq 2015.

3. Aune D, Navarro Rosenblatt D, Chan D, Vingeliene S, Abar L, Vieira A, Greenwood D, Bandera E, Norat T. Anthropometric factors and endometrial cancer risk: a systematic review and dose-response meta-analysis of prospective studies. Ann Oncol 2015; 26: 1635-1648.

4. A Epidemiology of lung cancer in Iran: sex difference and geographical distribution. Middle East J Cancer 2017; 8: 223-228.

5. Zhang Y, Liu H, Yang S, Zhang J, Qian L, Chen X. Overweight, obesity and endometrial cancer risk: results from a systematic review and meta-analysis. Int J Biol Markers 2014; 29: 21-29.

6. Mirzaei M, Sharifnia G, Khazaei Z, Sadeghi E, Fallahzadeh H, Namayandeh SM. Prevalence of general obesity and central adiposity and its related factors in adult population of Yazd. JSSU 2017; 25: 736-47.

7. Chaichian S, Khateri S, Moradi Y, Shadmani FK, Mansori K, Khazaei Z, Moradpour F, Varse F. Trends in cervical cancer incidence in Iran from 2003 to 2009. Middle East J Cancer 2017; 9: 57-63.

8. Carlson MJ, Thiel KW, Leslie KK. Past, present, and future of hormonal therapy in recurrent

endometrial cancer. Int J Womens Health 2014; 6: 429.

9. B. Serrano, M. Brotons, F.X. Bosch, L. Bruni, Epidemiology and burden of HPVrelated disease, Best Pract. Res. Clin. Obstet. Gynaecol. 47 (2017) 14-26.

10. H. zur Hausen, Condylomata acuminata and human genital cancer, Cancer Res. 36 (2 pt 2) (1976) 794.

11. World HPV Information Center, Human papillomavirus and related diseases report, ICO HPV Inf. Cent. Rep. (July) (2017) 1-334.

12. N. Egawa, K. Egawa, H. Griffin, J. Doorbar, Human papillomaviruses; epithelial tropisms, and the development of neoplasia, Viruses 7 (7) (2015) 3863-3890.

13. K. Van Doorslaer, Evolutionofthepapillomaviridae, Virology 445 (1-2) (2013) 11-20.

14. S.R. Georgescu, C.I. Mitran, M.I. Mitran, et al., New insights in the pathogenesis of HPV infection and the associated carcinogenic processes: the role of chronic inflammation and oxidative stress, J Immunol Res 2018 (2018) 1-10.

15. Semczuk A, Stenzel A and Baranowski W et al: Detection of human papillomavirus types 16 and 18 in human neoplastic endometrium: lack of correlation with established prognostic factors. Oncol Rep 2000; 7:905-910.

16. Czerwenka $\mathrm{K}^{1}$, Lu Y, Heuss F, Manavi M, Kubista E. Human papillomavirus detection of endometrioid carcinoma with squamous differentiation of the uterine corpus. Gynecol Oncol. 1996 May;61(2):210-4.

17. R. Zaino, S.G. Carinell and L.H. Ellenson et al. Who Classification of Tumours of Female Reproductive Organs, $4^{\text {th }}$ edition, 2014;5:125-128.

18. Colombo N, Preti E, Landoni F, et al. (2011). Endometrial cancer : ESMO clinical practice Guidelines for diagnosis, treatment and follow- up (2011). Ann of oncology 22(suppl 6) vi 35- vi 39.

19. Amands S, Bruege MD. (2013). Evaluating the utility of clinical criteria for the identification of lynch syndrome among endometrial cancer patients.Master thesis submitted to university of Texas.

20. Athraa Zaidan hassan, Sajaa J . AL-Khalidi, Basher S. Mohammed, Ali Hussein Mohammed Ali AL- Khafaji. Detection Human Papilloma 
Virus genotype (16/18) in Iraqi Women Patients with endometrial carcinoma by using Chromogen - Insitu Hybridization (CISH) Technique. Iraqi Journal of Cancer and Medical Genetics 2016;9:7481.

21. Kealy WF, Annis PG, Barry JA, Hogan JM. Adenoacanthoma of the endometrium: morphological changes induced by human papillomavirus. J Clin Pathol. 1990; 43:554-9.

22. Omer Asmaa M.(2010). Immunohistochemical study of hormonal receptors, HER-2 INEN and ki-67 expression in endometrial hyperplasia and endometrioid adenocarcinoma. Master thesis.

23. Sofie Leisby . (2013). The of PET/CT, MRI, Ultra sonography and biochemical analyses for pre operative staging of endometrial cancer pateints. Phd thesis submitted to university of copenttagen . faculty of health and medical science.

24. Fedrizzi EN, Villa LL, de Souza IV, Sebastião AP, Urbanetz AA, De Carvalho NS.Does human papillomavirus play a role in endometrial carcinogenesis? Int J GynecolPathol. 2009; 28:3227.

25. Andera GE, Stefanie G, Ioa NM, et al. (2011). Expression of HPV, steroid Receptors (ER $\alpha, E R \beta$, PR-A and PR-B) and hibin/Actin subunits $(\alpha, \beta$ A and $\beta B$ ) in adenosquamous Endometrial carcinoma . Anticancer research 27:2011-2018.

26. Fedrizzi EN, Villa LL, de Souza IV, Sebastião AP, Urbanetz AA, De Carvalho NS. Does human papillomavirus play a role in endometrial carcinogenesis? Int J Gynecol Pathol. 2009; 28:322-7.

27. Giantromanolaki A, Sivridis E, Papazoglou D, et al. (2007). Human papillomavirus in endometrial adenocarcinoma: infectious agent or mere "passenger" ? infect Dis obstet Gynecol.; 31:60549-53.

28. Frazer IH. (2009).Interaction of human papillomaviruses with the host immune system: a well evolved relationship. Virology. 384(1):410 414.

29. Karadayi N, Gecer M, Kayahan S, et al. (2013). Association between human papilloma and endometrium adenocarcinoma. Med oncol . 30(3): 597.
30. Karadayi N, Gecer M and Kayahan S. et al. Association between human papillomavirus and endometrial adenocarcinoma. Med Oncol. 2013; 30 (3):597.

31. Hording U, Daugaard S, Visfeldt J. Adenocarcinoma of the cervix and adenocarcinoma of the endometrium: distinction with PCR-mediated detection of HPV DNA. APMIS. 1997;105(4):3136.

32. Olesen TB, Svahn MF and Faber MT et al. Prevalence of human papillomavirus in endometrial cancer: a systematic review and meta-analysis. Gynecol Oncol. 2014; 134:206 -15.

33. W. Qu, G. Jiang, Y. Cruz, et al., "PCR detection of human papillomavirus: comparison between MY09/MY11 andGP5+/GP6+ primer systems," Journal of Clinical Microbiology,vol. 35, no. 6, pp. 1304-1310, 1997.

34. Mohammed A. Abu-Lubad, Dua'a A. Jarajreh and Ghada F. Helaly et al. Human papillomavirus as an independent factor of invasive cervical and endometrial carcinomas in Jordan. Journal of Infection and Public health, 2020;13: 613-618.

35. Saad H.Mohammed, Basim S. Ahmed and Sura D. Dawood et al. Association of CCND1 and HRHPV16/18 in endometrial tumors.Iraqi Journal of Cancer and Medical Genetics, 2015;8:143-151.

36. Giatromanolaki A, Sivridis E, Papazoglou D, Koukourakis MI, Maltezos E. Human papillomavirus in endometrial adenocarcinomas: infectious agent or a mere"passenger"? Infect Dis Obstet Gynecol. 2007; 2007:60549.

37. M. Fujita, K. R. Shroyer, N. E. Markham, et al., "Association of human papillomavirus with malignant and premalignant lesions of the uterine endometrium," Human Pathology, vol. 26, no. 6, pp. 650-658, 1995.

38. T. Zbroch, P. Knapp, and P. Knapp, "Human papillomavirus (HPV) infection in the pathology of the endometrium. Role of immunological activation in antiviral and antineoplastic defense," Medycyna Wieku Rozwojowego, vol. 6, no. 1, pp. 43-55, 2002. 